\title{
Experience with art adherence couselling at muhimbili national hospital, Dar es Salaam, Tanzania
}

Joan Karomba

From $16^{\text {th }}$ International Symposium on HIV and Emerging Infectious Diseases

Marseille, France. 24-26 March 2010

\section{Background}

In July 2004, the Tanzania of Health initiated Pilot care and treatment program at the Muhimbili National Hospital. $(\mathrm{MNH})$. The pilot fg program was designed to inform the National Scale - up antiretroviral therapy (ART). The goal of the pilot program was to initiate 3000 patients on ART over a period of three months. We report our initial experience in offering adherence counseling to these clients.

\section{Methods}

Clients were seen at the MNH HIV/AIDS clinic from July 2004 to October 2004 all eligible patients were offered ART adherence counseling prior to therapy initiation and thereafter at every re-fill appointment. ART was initiated only after both the counselor and clients having been satisfied with the readiness of the clients to start the therapy.

Assessment of degree of adherence was by the selfreport as well as pharmacy re-fill performed quantitavely, while patients attitudes to the exercise and problems associated with offering adherence counseling were ascertained using qualitative methods

\section{Results}

By $30^{\text {th }}$ of September 2004, 1,286 patients were enrolled in care and 881 patients were put in ART having undergone adherence counseling. More than $65 \%$ of the enrollment occurred in the first eight weeks of the pilot program, indicating strong demand for HIV care and treatment services among people living with HIV/AIDS (PLWHA) in Dar es Salaam. By the end of October
2004, a total of 1655 patients were in care and 1,172 (70.82\%) on ART. Patients on ART included 59\% women $31 \%$ men and $10 \%$ children. The loss to followup rate was $11 \%$.

Overall, clients reported good satisfication with the quality of care offered at the clinic, and $85 \%$ of clients demonstrated good understanding on issue pertaining adherence to ART, at follow-up, it was noted clients achieved 95\% adherence with ART. However, long clients waiting - times merged as a significant problem when the clinic caseload exceeded 200 visits per day.

\section{Conclusion}

The achievements and experience of the MNH ART clinic showed that good adherence is possible in a resource poor setting with extreme staff shortages and should be started early before. Initiation of ARV therapy.

However, as such programe scale-up, they should be prepared to face up huge practical challenges.

Published: 11 May 2010

doi:10.1186/1742-4690-7-S1-P56

Cite this article as: Karomba: Experience with art adherence couselling at muhimbili national hospital, Dar es Salaam, Tanzania. Retrovirology 2010 7(Suppl 1):P56.

Correspondence: jkarombatz@yahoo.com

Muhimbili National Hosp, Dar Es Salaam, United Republic of Tanzania 